\title{
A CONSTRUÇÃO DAS POLÍTICAS PÚBLICAS DE SAÚDE: COMPETÊNCIAS ADMINISTRATIVAS, SOLIDARIEDADE PROCESSUAL E DESAFIOS PARA 0 FORTALECIMENTO DO SUS
}

The development of public health care policy: administrative competences, procedural joint liability, and challenges to improving Brazilian National Public Health System

${ }^{1}$ Pontifícia Universidade Católica de São Paulo. São Paulo/SP, Brasil. Correspondência: Patrícia Ulson Pizarro Werner. E-mail: pwerner@sp.gov.br.

Recebido em: 04/08/2015. Aprovado em: 13/08/2015. 


\section{RESUMO}

O artigo apresenta uma reflexão sobre a posição do Poder Judiciário brasileiro em reconhecer a responsabilidade solidária dos entes federativos na prestação dos serviços no Sistema Único de Saúde (SUS). Pretende-se demonstrar a necessidade de não generalizar essa interpretação nos casos de ações judiciais que tenham a força de alterar uma política pública. A questão da solidariedade não deve ser vista aqui pelo ângulo processual, mas sim, de maneira inversa, em relação ao ente da federação que sozinho continuará a não dar conta de atender a demanda. Diante das incontestáveis limitações orçamentárias e de recursos humanos e estruturais, o fortalecimento da promoção do diálogo institucional criará um sistema coerente, transparente e com qualidade crescente, e estimulará a construção de políticas públicas de saúde planejadas de modo legítimo e durador.

\section{Palavras-Chave}

Competências; Federalismo; Políticas Públicas; Saúde Pública.

\section{ABSTRACT}

This study presents a reflection on the position of the Brazilian Judicial Branch in recognizing joint liability of government entities in providing services as part of the Brazilian National Publich Health Systems (SUS). This study aims to demonstrate the need to avoid generalizing this interpretation in cases of judicial actions that have the power to change public policy. The question of joint liability should not be considered only from the procedural angle, but conversely, in terms of the fact that the federal government cannot continue to meet demands alone. In light of these unquestionable limitations in terms of the budget, human resources, and structure, strengthening institutional dialog will create a consistent, transparent, and improved system and it will stimulate the legitimate and long-lasting development of public health policies.

\section{Keywords}

Competences; Federalism; Public Health; Public Policy. 


\section{EMENTAS}

AGRAVO DE INSTRUMENTO. DIREITO PÚBLICO NÃO ESPECIFICADO. AÇÃO CIVIL PÚBLICA. DIREITO À SAÚDE. MUNICÍPIO DE PELOTAS. HOSPITAL DE PRONTO SOCORRO. MELHORIA DO ATENDIMENTO. RESPONSABILIDADE SOLIDÁRIA DOS ENTES FEDERADOS. CHAMAMENTO AO PROCESSO DA UNIÃO E ERGS, BEM COMO DOS MUNICÍPIOS VIZINHOS. DESCABIMENTO. CONTROLE JUDICIAL. EFETIVAÇÃO DAS POLÍTICAS PÚBLICAS CONSTITUCIONAIS E LEGAIS. INAÇÃO ADMINISTRATIVA. MÍNIMO EXISTENCIAL. TRANSGRESSÃO DA AUTORIDADE CONSTITUCIONAL E LEGAL. CARÁTER VINCULANTE E COGENTE. TRANSFERÊNCIA EXCEPCIONAL DOS PACIENTES E AQUISIÇÃO DE LEITOS NA REDE PARTICULAR. CABIMENTO. MULTA DIÁRIA EM CASO DE DESCUMPRIMENTO. POSSIBILIDADE. REDUÇÃO DO VALOR. Preliminar de chamamento ao processo I - O sistema de saúde é encargo de todos os entes federados, sem atribuições exclusivas e excludentes. Trata-se de responsabilidade solidária, cabendo ao cidadão demandar contra qualquer deles, conjunta ou separadamente. Inteligência dos artigos 196, caput, e art. 198, $\$ 1^{\circ}$, ambos da Constituição da República; art. $7^{\circ}$, XI, da Lei Federal no 8.080/90 e art. 241 da Constituição Estadual. II - Não obstante a solidariedade, na esteira da posição adotada no âmbito da Corte Especial do e. STJ, em sede de recurso representativo de controvérsia - art. 543-C do CPC -, não se afigura factível o chamamento ao processo dos municípios vizinhos nas ações de prestação de serviços de saúde. Precedentes da jurisprudência. Mérito I - Consoante entendimento do e. STF, cabível o controle judicial para a efetivação das políticas públicas assecuratórias do mínimo existencial da população, em especial o direito à saúde e a dignidade da pessoa humana. Cumpre frisar a atribuição do Judiciário na efetivação dos direitos individuais e coletivos de estatura constitucional, tendo em vista a índole vinculativa e consequente limitação da discricionariedade da atuação administrativa e a primazia da Constituição da República, a afastar qualquer sombra de violação à separação dos poderes da República, diante do conflito entre os valores constitucionalmente estabelecidos. Neste sentido, devida a adequação do atendimento médico de urgência no Pronto Socorro de Pelotas, no âmbito do Sistema Único de Saúde - SUS. II - A imposição de obrigação de transferência dos pacientes do Pronto Socorro para outro hospital da rede pública, em $72 \mathrm{~h}$ - leito clínico -, ou $48 \mathrm{~h}$ - leito UTI -, e a obrigação excepcional de aquisição de leitos na rede particular nos casos de insucesso, configura medida mínima para a concretização das políticas estabelecidas, sopesada a notória dificuldade no gerenciamento da viabilização dos escassos recursos públicos, as quais sucumbem frente a magnitude do direito cotejado. IV - Cabível a fixação de multa diária em face da Fazenda Pública, quando necessária à efetivação de decisão judicial. Precedentes do STF e deste Tribunal. V - Redução do valor arbitrado, na esteira dos julgados deste Tribuna parcialmente provido. (TRIBUNAL DE JUSTIÇA DO RIO GRANDE DO SUL, AGRAVO DE 
INSTRUMENTO N. 70058136292, TERCEIRA CÂMARA CÍVEL, RELATOR: EDUARDO DELGADO, JULGADO EM 25/09/2014)

RECURSO EXTRAORDINÁRIO. CONSTITUCIONAL E ADMINISTRATIVO. DIREITO À SAÚDE. TRATAMENTO MÉDICO. RESPONSABILIDADE SOLIDÁRIA DOS ENTES FEDERADOS. REPERCUSSÃO GERAL RECONHECIDA. REAFIRMAÇÃO DE JURISPRUDÊNCIA. O tratamento médico adequado aos necessitados se insere no rol dos deveres do Estado, porquanto responsabilidade solidária dos entes federados. O polo passivo pode ser composto por qualquer um deles, isoladamente, ou conjuntamente. (SUPREMO TRIBUNAL FEDERAL, RE N. 855178 RG, RELATOR: MIN. LUIZ FUX, JULGADO EM 05/03/2015)

\section{Introdução}

O projeto constitucional do Sistema Único de Saúde (SUS) vem obtendo conquistas consideráveis, como a construção de uma sólida estrutura legislativa e o avanço na dimensão interpretativa da extensão do próprio conceito de direito fundamental à saúde.

Por outro lado, há muito o que se construir para a produção de políticas públicas fortes e duradouras, com a otimização da articulação entre "atores, instituições e ideias"', o que implica na necessidade de compreensão da construção dos ciclos do SUS de forma integral, principalmente no que se refere às questões de distribuição de competências na Federação e ao fortalecimento de suas estruturas organizacionais e deliberativas.

O julgado em comento é muito rico para demonstrar facetas do problema, sendo significativas as palavras do desembargador relator Eduardo Delgado para nos conduzir nesta reflexão: "Eminentes Colegas. A questão é tormentosa, pois envolve a eficiência do Sistema Único de Saúde - SUS - no Pronto-Socorro do Município de Pelotas, em especial a estruturação e o gerenciamento"2.

\section{A origem da decisão judicial}

Para melhor compreender o julgamento em análise, registra-se que a origem da lide é uma ação civil pública ajuizada pelo Ministério Público do Estado do Rio Grande do Sul em face do Município de Pelotas, com o fim compeli-lo a "prestar de forma adequada, contínua, eficaz e segura à população pelotense todos os serviços de saúde no âmbito do Sistema Único de Saúde - SUS”’3.

\footnotetext{
${ }^{1}$ HOWLETT, Michael; RAMESH, M.; PERL, Anthony. Política pública: seus ciclos e subsistemas: uma abordagem geral. Rio de Janeiro: Elsevier, 2013.

${ }^{2}$ Acórdão em TRIBUNAL DE JUSTIÇA DO ESTADO DO RIO GRANDE DO SUL. p. 14. Disponível em: <http://www. tjrs.jus.br/busca/?tb=proc>. Acesso em: 20 jul. 2015.

${ }^{3}$ Id. Ibid., p. 3.
} 
O magistrado foi pessoalmente ao nosocômio para fazer a inspeção judicial e concedeu o pedido liminar para: (a) reconhecer que o pedido inicial tem "conteúdo absolutamente subjetivo nas expressões adequado, eficaz e seguro. Assim, fosse apenas isso, restaria difícil afastar o vício do artigo 286, caput do Código de Processo Civil (CPC), que exige a apresentação de pedido certo e determinado"4; e (b) apesar da identificação formal da impropriedade do pedido, o juízo, "considerando a natureza da demanda e a relevância de seu objeto", elegeu cinco pontos para delimitar o objeto da ação: (i) transferência dos pacientes para hospital geral, no prazo de 48 horas contados da internação; (ii) retirada do pronto atendimento (PA) das dependências do pronto-socorro (PS); (iii) organização do espaço físico, com a divisão dos leitos por sexo e gravidade; (iv) aquisição de leitos, materiais e equipamentos necessários ao efetivo tratamento e atendimento, com a manutenção do prontuário médico, junto ao paciente; e (v) atendimento individual dos pacientes.

Por outro lado, negou o pedido de chamamento de terceiros ao processo, ou seja, dos municípios da região que utilizam o estabelecimento para atendimento da população local, com fundamento na solidariedade entre os membros da Federação. Porém, reconheceu que o local é a "única porta aberta de plantão $24 \mathrm{~h}$ na região" e, assim, para "salvaguardar a saúde e a dignidade das pessoas que encontram-se no PS", deferiu a liminar impondo ao Município as várias obrigações referidas, indeferindo somente os pedidos de (a) aquisição de leitos, materiais e equipamentos, assim como a manutenção do prontuário médico junto ao paciente, por considerar suficiente a manutenção da pulseira de identificação no pulso do paciente e (b) quanto ao atendimento individual aos pacientes, determinou a produção de nova provas.

Inconformado, o munícipio interpôs recurso de agravo de instrumento, com os seguintes fundamentos, sintetizados: (a) o PS é a única instituição do SUS na cidade e atende mais de 23 munícipios da zona sul do estado, com sobrecarga ao poder local; (b) reiterou a tese do chamamento ao processo da União, do estado e dos municípios da região atendidos pelo Município de Pelotas com base na insuficiência de recursos financeiros repassados, justamente por serem solidários no atendimento regional; (c) destacou a invasão do ato exclusivo médico na eleição de atos prioritários de internação; (d) salientou a "comercialização dos serviços de saúde privados através de liminares judicias" no local; e, por fim, (e) mencionou a natureza draconiana das multas impostas.

O tribunal julgou parcialmente procedente o recurso para alterar a decisão recorrida, apenas com a redução da multa para o valor de $\mathrm{R} \$ 10.000,00$.

${ }^{4}$ TRIBUNAL DE JUSTIÇA DO ESTADO DO RIO GRANDE DO SUL. p. 4. Disponível em: <http://www.tjrs. jus.br/busca/?tb=proc>. Acesso em: 20 jul. 2015.

${ }^{5}$ Id. Ibid., p. 12. 


\section{A responsabilidade solidária entre os entes da federação}

Diante da complexidade da decisão, elege-se como objeto de reflexão apenas o tema do reconhecimento da responsabilidade solidária dos entes federados, por residir aqui a questão central de análise do sucesso ou não das metas fixadas sob a ótica do estudo sistêmico das políticas públicas de saúde.

O objetivo é provocar o debate sobre a necessidade de criar mecanismos para produzir decisões administrativas e judiciais com foco em ajudar a superar os problemas de distribuição de competências na Federação brasileira, com a construção de paradigmas que promovam o fortalecimento dos órgãos estruturais do SUS e potencializem o diálogo interinstitucional. Afinal, quando o acórdão menciona que o litígio é sobre a "estrutura e gerenciamento" do PS, denota-se que haverá a análise do ciclo integral da política pública, desde a formulação e as escolhas dos instrumentos até a própria avaliação. Assim, há de se notar que a decisão judicial resultante nada mais é do que uma tomada de decisão sobre o ciclo integral da política pública, com pleno poder de alterá-la.

\section{A solidariedade processual - repercussão geral do STF}

Uma questão tormentosa no Brasil continua sendo a dificuldade de se respeitarem as competências federativas fixadas. Doutrinariamente, sabe-se que o Federalismo deve buscar o "equilíbrio entre tarefas e recursos", o que destoa da realidade - em que se verifica a concentração real de poderes no âmbito da União e a permanência enfraquecida da autonomia dos municípios, uma construção histórica e cultural que resvala, de forma muito grave, no gerenciamento concreto das políticas públicas de saúde.

O grande número de ações judicias sobre o tema levou o Supremo Tribunal Federal (STF) a constatar a existência da repercussão geral - ou seja, diante da relevância jurídica, política, social e econômica envolvida, aplicou a ferramenta processual para fixar a interpretação cabível sobre o mérito da questão a ser adotada pelas instâncias inferiores em casos idênticos ${ }^{7}$.

O julgamento pelo Plenário do STF ocorreu no dia 5 de março de 2015, com a adoção do relatório do ministro Luiz Fux, no sentido de reafirmar a

\footnotetext{
${ }^{6}$ RAMOS, Dircêo Torreccillas. Federação: tarefas, recursos, prazos, controle para combater a corrupção. In: RAMOS, Dircêo Torreccillas (Org.). O federalista atual: teoria do federalismo. Belo Horizonte: Arraes Editores, 2013. p. 218.

7“Art. 102. Compete ao Supremo Tribunal Federal, precipuamente, a guarda da Constituição, cabendo-Ihe: (...) $\S 3^{\circ}$ No recurso extraordinário o recorrente deverá demonstrar a repercussão geral das questões constitucionais discutidas no caso, nos termos da lei, a fim de que o Tribunal examine a admissão do recurso, somente podendo recusá-lo pela manifestação de dois terços de seus membros. (Incluída pela Emenda Constitucional n 45, de 2004)". BRASIL. Constituição da República Federativa do Brasil de 1988. Disponível em: <http:// www.planalto.gov.br/ccivil_03/constituicao/ConstituicaoCompilado.htm>. Acesso em: 16 set. 2015.
} 
jurisprudência de que o "tratamento médico adequado aos necessitados se insere no rol dos deveres do Estado, porquanto responsabilidade solidária dos entes federados. O polo passivo pode ser composto por qualquer um deles, isoladamente ou conjuntamente"8.

Destaca-se que a decisão restringiu seu objeto à análise da legitimidade do polo passivo de demanda e, nesse contexto, fixou o entendimento de que a composição pode ser compreendida por todos ou qualquer um dos entes da Federação visando ao tratamento médico dos necessitados, notadamente carentes ${ }^{9}$.

A posição adotada pela Corte Constitucional é coerente ao tratar o tema sob o aspecto processual e coaduna-se com o princípio constitucional do acesso à Justiça. Efetivamente, o usuário do SUS não pode ser prejudicado duplamente: em primeiro lugar, pela falta de acesso ao serviço de saúde; e, em segundo, não tendo acesso ao Poder Judiciário, por problemas de ordem processual formal.

\section{Competência material comum: organização estrutural interna}

O raciocínio que se pretende construir é de que a conjuntura é bem diferente quando o objeto da ação judicial é a discussão da política pública em sua essência - caso em que haverá a necessidade de conhecer e aplicar regras e competências legais fixadas para cada ente da federação, de modo a fortalecer o desenvolvimento do SUS, pois a decisão judicial terá o poder de alterar toda a escolha de instrumentos, composições políticas e administrativas efetuadas.

No momento em que há a constatação das dificuldades concretas de diálogo e colaboração entre os atores político-administrativos, segundo papéis fixados em lei, deve-se refletir sobre como melhorar a qualidade dos serviços e torná-los cada vez mais acessíveis à comunidade, o que pressupõe o fortalecimento da organização nuclear do sistema.

Para tanto, é essencial a análise da competência material comum prevista na Constituição Federal de 1988 e na legislação ordinária, pois nelas estão definidas as regras de cooperação entre os entes federativos de modo a promover o equilíbrio do desenvolvimento e do bem-estar em âmbito nacional ${ }^{10}$ - ou seja, devem ser

\footnotetext{
${ }^{8}$ BRASIL. Supremo Tribunal Federal. Recurso Especial n. 855178 RG/PE. Relator Ministtro Luiz Fux. Disponivel em: <http://www.stf.jus.br/portal/jurisprudencia/listarJurisprudencia.asp?s1=\%28direito++e+sa\%F Ade++e+responsabilidade+solid\%E1ria\%29\&base=baseRepercussao\&url=http://tinyurl.com/oqpq9sn>. Acesso em: 26 jul. 2015.

${ }^{9}$ BRASIL. Supremo Tribunal Federal. Repercussão Geral no Recurso Extraordinário 855.178 Sergipe. Disponivel em: <http://redir.stf.jus.br/paginadorpub/paginador.jsp?docTP=TP\&doclD=8015671>. Acesso em: 26 jul. 2015.

10 “Art. 23. É competência comum da União, dos Estados, do Distrito Federal e dos Municípios: (...) I - zelar pela guarda da Constituição, das leis e das instituições democráticas e conservar o patrimônio público; (...) Parágrafo único. Leis complementares fixarão normas para a cooperação entre a União e os Estados, o Distrito Federal e os Municípios, tendo em vista o equilíbrio do desenvolvimento e do bem-estar em âmbito
} 
consideradas as reais possibilidades administrativas e orçamentárias dos diversos atores de modo que "não se atribua a algum deles, em nome da responsabilidade solidária, tarefa que não possa cumprir”"1.

\section{A evolução do SUS depende do fortalecimento de suas estruturas}

Para a análise dos reflexos da presente decisão e de outras similares, não vamos adentrar às calorosas controvérsias doutrinárias e jurisprudenciais sobre a possibilidade ou não de intervenção do Poder Judiciário na implementação das políticas públicas, temas conhecidos como "judicialização" e "ativismo judicial".

Traça-se aqui um corte epistemológico pragmático, no sentido de reconhecer a tendência do Poder Judiciário brasileiro de aceitar demandas individuais ou coletivas que adentram no mérito das políticas públicas de saúde, citando-se como paradigmas as conclusões da Audiência Pública da Saúde, realizada pelo STF em $2009^{12}$, a atuação do Conselho Nacional de Justiça, através das Jornadas de Direito da Saúde, e as reiteradas decisões judiciais sobre a questão; de modo que a tendência é analisar o Poder Judiciário como um ator visível e importante na construção das políticas públicas. Como assevera Bucci, ao analisar o papel político-institucional desse controle em um cenário democrático: "Não se trata de conceber o Poder Judiciário como mera arena de conflitos, mas respeitar que a exigência judicial de direitos seja uma alternativa possível"13.

Apesar da constatação dessa propensão, cabe registrar que o melhor caminho a seguir para tratar as dificuldades operacionais e a qualidade das políticas públicas ainda é investir no desenvolvimento de "meios consensuais de solução de conflitos"14 dentro da própria administração, considerando que a estrutura do SUS conduz para o aprimoramento dessa dinâmica através dos conselhos de saúde, das comissões intergestores e dos polos de participação da comunidade. Como exemplo, cita-se a experiência da Advocacia-Geral da União na criação das Câmaras de Conciliação e Arbitragem da Administração Federal (CCAF), justamente com a finalidade de evitar a judicialização e possibilitar a melhor articulação das políticas públicas. As CCAF visam a institucionalizar a prática de um novo conceito de boas práticas de composição de conflitos administrativos entre órgãos da administração pública federal, bem como entre estes e a administração

nacional. (Redação dada pela Emenda Constitucional n 53, de 2006)”. BRASIL. Constituição da República Federativa do Brasil de 1988, cit.

${ }^{11}$ ALMEIDA, Fernanda Dias Menezes de. Competências na Constituição de 1988. São Paulo: Atlas, 2013. p. 119.

${ }^{12}$ Ver estudo de RAIS, Diogo. A sociedade e o Supremo Tribunal Federal: o caso das audiências públicas. São Paulo: Fórum, 2012. p. 103-112.

${ }^{13} \mathrm{BUCCl}$, Maria Paula Dallari. Fundamentos para uma teoria jurídica das políticas públicas. São Paulo: Saraiva, 2013. p. 197.

${ }^{14}$ SOUZA, Luciane Moessa de. Meios consensuais de solução de conflitos envolvendo entes públicos: negociação, mediação e conciliação. Belo Horizonte: Ed. Fórum, 2012. 
pública dos estados, Distrito Federal e municípios ${ }^{15}$, fortalecendo a criação de mecanismos de "diálogos institucionais"16.

Para tanto, a legislação ordinária do SUS fornece instrumentos preciosos para desenvolver e aperfeiçoar as estruturas do sistema e lidar com a escassez - entre eles, os consórcios administrativos intermunicipais ${ }^{17}$, cujo objetivo é promover ações conjuntas de serviços de saúde que lhes correspondam, com incentivo de integração de recursos, técnicas e práticas voltados para a cobertura total das ações de saúde.

No âmbito institucional, é necessário adotar soluções que fortaleçam a atuação dos órgãos deliberativos, tais como as comissões intergestores - que funcionam como foros de negociação e pactuação, justamente entre os atores que devem decidir sobre os aspectos operacionais, financeiros e administrativos da gestão compartilhada ${ }^{18}$.

O papel central do Estado no SUS é analisar a situação de grupos de municípios, de modo a planejar a melhor estrutura entre todos para viabilizar - apesar da escassez financeira, estrutural e de recursos humanos - a distribuição dos serviços a fim de melhor atender a todos.

${ }^{15}$ BRASIL. Advocacia Geral da União. Ato Regimental n. 5, de 27 de setembro de 2007. Disponível em: <file:///C:/Users/D\%C3\%A9bora\%20Martins/Downloads/ato_regimental_agu_n-_5_de_27_de_setembro_de_2007_-_ato_regimental_consolidado.pdf>. Acesso em: 22 set. 2015; BRASIL. Decreto n. 7.392, de 13 de dezembro de 2010. Aprova a Estrutura Regimental e o Quadro Demonstrativo dos Cargos em Comissão da Advocacia-Geral da União, aprova o Quadro Demonstrativo dos Cargos em Comissão da Procuradoria-Geral Federal e remaneja cargos em comissão para a Advocacia-Geral da União e para a Procuradoria-Geral Federal. Disponível em: <http://www.planalto.gov.br/ccivil_03/_Ato2007-2010/2010/ Decreto/D7392.htm>. Acesso em: 22 set. 2015.

${ }^{16} \mathrm{BUCCl}$, Maria Paula Dallari. op. cit., p. 199.

17 “Art. $9^{\circ}$ A direção do Sistema Único de Saúde (SUS) é única, de acordo com o inciso I do art. 198 da Constituição Federal, sendo exercida em cada esfera de governo pelos seguintes órgãos: I - no âmbito da União, pelo Ministério da Saúde; II - no âmbito dos Estados e do Distrito Federal, pela respectiva Secretaria de Saúde ou órgão equivalente; e III - no âmbito dos Municípios, pela respectiva Secretaria de Saúde ou órgão equivalente. Art. 10. Os municípios poderão constituir consórcios para desenvolver em conjunto as ações e os serviços de saúde que lhes correspondam. $\S 1^{\circ}$ Aplica-se aos consórcios administrativos intermunicipais o princípio da direção única, e os respectivos atos constitutivos disporão sobre sua observância. $\S 2^{\circ}$ No nível municipal, o Sistema Único de Saúde (SUS), poderá organizar-se em distritos de forma a integrar e articular recursos, técnicas e práticas voltadas para a cobertura total das ações de saúde. BRASIL. Lei Federal n. 8.080, de 19 de setembro de 1990. Dispõe sobre as condições para a promoção, proteção e recuperação da saúde, a organização e o funcionamento dos serviços correspondentes e dá outras providências. Disponível em: <http://www.planalto.gov.br/ccivil_03/Leis/L8080.htm>. Acesso em: 22 set. 2015.

18 “Art. 14-A. As Comissões Intergestores Bipartite e Tripartite são reconhecidas como foros de negociação e pactuação entre gestores, quanto aos aspectos operacionais do Sistema Único de Saúde (SUS). (Incluído pela Lei n 12.466, de 2011). Parágrafo único. A atuação das Comissões Intergestores Bipartite e Tripartite terá por objetivo: (Incluído pela Lei $n^{\circ} 12.466$, de 2011). I - decidir sobre os aspectos operacionais, financeiros e administrativos da gestão compartilhada do SUS, em conformidade com a definição da política consubstanciada em planos de saúde, aprovados pelos conselhos de saúde; (Incluído pela Lei n 12.466 , de 2011). II - definir diretrizes, de âmbito nacional, regional e intermunicipal, a respeito da organização das redes de ações e serviços de saúde, principalmente no tocante à sua governança institucional e à integração das ações e serviços dos entes federados; (Incluído pela Lei $n^{\circ} 12.466$, de 2011). III - fixar diretrizes sobre as regiões de saúde, distrito sanitário, integração de territórios, referência e contrarreferência e demais aspectos vinculados à integração das ações e serviços de saúde entre os entes federados. (Incluído pela Lei $n^{\circ}$ 12.466, de 2011). BRASIL. Lei Federal n. 8.080, de 19 de setembro de 1990, cit. 
No caso em análise, a estrutura administrativa demonstrou suas dificuldades de implementar e gerir a complexidade dos subsistemas municipais, considerando-se, por exemplo, que o Estado do Rio Grande do Sul já reconheceu, através da Comissão Intergestores Regional (CIR), que o Município de Pelotas atende a uma região que abrange mais 22 municípios ${ }^{19}$. Dessa maneira, limitar a lide aos "munícipes pelotenses"20 é colaborar para a manutenção do insucesso constatado, sem ajudar a criar mecanismos legais para lidar com problemas regionais ${ }^{21}$.

Pergunta-se, então, se é razoável sobrecarregar o munícipio, núcleo do sistema regional, com funções que deveriam ser solucionadas por diretivas fixadas pelas comissões intergestores. Esse aspecto pode ser confundido com solidariedade processual? Será que a ação civil pública não deveria justamente compensar a falha do diálogo institucional, tanto é que houve a necessidade de acesso ao Poder Judiciário para mediar a lide?

O que se pretende demonstrar é a necessidade de estimular o compromisso das instituições que planejam e avaliam as políticas públicas e que têm o poder de alterá-las - como é o caso da força de uma decisão judicial -, encorajando a otimização de diálogos e vínculos de responsabilidade dos órgãos, a fim de promover novas ideias de aperfeiçoamento de políticas públicas. Esse processo deve envolver os atores principais, em especial órgãos da própria administração, na mediação da difícil relação entre os entes da Federação brasileira, ajudando, assim, a superar esse obstáculo histórico. Segundo estudos de Howlett, Ramesh e Perl:

O Federalismo tem sido citado como uma razão fundamental para explicar a baixa capacidade política de muitos setores político-administrativos em países como os Estados Unidos e Canadá [...] os governos acham difícil desenvolver políticas consistentes, coerentes, porquanto as políticas nacionais, na maioria das áreas, exigem acordo intragovernamental, envolvendo negociações complexas, extensas e consumidoras de tempo que nem sempre são bem-sucedidas. [...] Além disso, ambos os governos estão sujeitos a revisão judicial imprevisível de suas medidas, o que restringe ainda mais a habilidade do governo de realizar seus objetivos. [...] Assim,

${ }^{19}$ Resolução CIR n. 39, de 16 de maio de 2012, que à época atendia a 845.135 pessoas.

${ }^{20}$ Não se está criticando o mérito da decisão do Município do Pelotas, que ainda está em andamento, com a produção de provas, mas sim, utilizando o dilema exposto pelos magistrados como referência.

${ }^{21}$ Como apontado no Relatório do Conselho Municipal de Saúde, desde 2006, o mais importante para a região seria provocar um diálogo conceitual para as estruturas do Estado que trabalham com o transporte de doentes na região: “Que a Secretaria Municipal de Saúde [...] promova um fórum de discussão sobre o Pronto-Socorro com a participação de todas as partes diretamente interessadas (SAMU, UNIMED, ECOSUL, Serviços Autônomos de Ambulâncias, hospitais de retaguarda, Prefeituras da região de cobertura), Sindicatos, Conselho Regional de Saúde, Conselho Regional de Enfermagem e a sociedade em geral envolvendo as organizações da sociedade civil". PELOTAS. Conselho Municipal de Saúde. Relatório sobre o Pronto Socorro de Pelotas, elaborado pelo Conselho Municipal de Saúde em atendimento à deliberação de plenária realizada em 21 de dezembro de 2006 (Ata 27/2006). Disponível em: <http://www.pelotas.rs.gov. br/cmspel/relatorio_psp.pdf>. Acesso em: 22 set. 2015. 
o federalismo torna a policy-making um affair prolongado e muitas vezes rancoroso, na medida em que os governos disputam questões judiciais ou estão envolvidos em extensas negociações intergovernamentais ou de litigio constitucional. É possível que diferentes governos em um mesmo país tomem decisões contraditórias que podem enfraquecer ou anular os efeitos de uma política ${ }^{22}$.

\section{Estimular a aprendizagem e avaliação das políticas públicas de saúde}

Na realidade, uma ação civil pública que visa à prestação de serviços de saúde de "forma adequada, contínua, eficaz e segura à população pelotense" partiu do pressuposto de que a avaliação da política pública até então implantada não teve o êxito esperado. Ou melhor, chegou a uma avaliação final negativa, com o reconhecimento de que os instrumentos utilizados não foram aptos a alcançar o objetivo fixado.

Para tanto, reconheceu ser necessária a escolha de novos instrumentos de policy-making, que devem estar "estreita e cuidadosamente relacionadas aos objetivos políticos", de modo que "quaisquer novos objetivos e ferramentas também têm que estar integrados de forma cuidadosa às políticas existentes, para que a implementação seja bem-sucedida"23.

Assim, todos os atores envolvidos na formatação de um novo desenho da política pública via judicial (policy design) devem, ao tomarem decisões corretivas, empenhar-se para "conseguir uma conciliação ou combinação ótima de objetivos e meios no processo de implementação com vistas a alcançarem esses objetivos com êxito, mas esse processo está carregado de desafios e riscos de insucesso" 24 - motivo pelo qual o êxito da decisão, administrativa ou judicial, depende da capacidade que o Estado tem de enfrentar os problemas. Nesse contexto, o acórdão representa a "avaliação judicial" de revisão da ação do governo ${ }^{25}$, e cabe ao Poder Judiciário atuar com a responsabilidade de ser um agente de fortalecimento das instituições do SUS, com a finalidade de gerar a "aprendizagem"26 técnica e política para a evolução de cada estágio dos ciclos de políticas públicas de saúde.

Todos os atores que fazem parte da construção do projeto constitucional SUS devem conhecer bem seus preceitos e sua estrutura, de modo a construir decisões que levem a seu fortalecimento. Essas decisões precisam reconhecer e lidar claramente com os temas da escassez de infraestrutura física, humana e orçamentária, segundo o binômio universalidade e igualdade, a fim de superar os padrões políticos e administrativos que impedem a eficácia e legitimidade da construção do SUS, pois o:

\footnotetext{
${ }^{22}$ HOWLETT, Michael; RAMESH, M.; PERL, Anthony. op. cit., p. 68.

${ }^{23}$ Id. Ibid., p. 192.

${ }^{24}$ Id. Ibid., p. 193.

${ }^{25}$ Id. Ibid., p. 211.

${ }^{26}$ Id. Ibid., p. 214-219.
} 
Estado tem que ter um serviço público de alta capacidade operando no interior de um subsistema grande e complexo para que aconteça a "aprendizagem social". Quando o funcionalismo é mal treinado e não tem experiência e os subsistemas são fechados, não se pode esperar senão formas perfunctórias ou limitadas de aprendizagem ${ }^{27}$.

Há a necessidade de promover a "aprendizagem social", no processo de análise das políticas públicas, pelos três Poderes, devendo-se considerar: a existência de um arcabouço legal que define quem tem atribuição para fazer o quê; e como as ações de saúde devem ser compostas para se tornarem viáveis, conforme se pode notar com clareza, por exemplo, nas Normas Operacionais (NOAS-SUS), tantas vezes desconsideradas.

$\mathrm{Na}$ avaliação direta das políticas públicas via Poder Judiciário, não pode haver a responsabilidade solidária genérica entre os entes Federais; há, sim, a esperança central de ajuda na promoção da falha do diálogo institucional. A questão da solidariedade aqui não deve ser vista pelo ângulo processual, mas sim, de maneira inversa, a solidariedade em relação ao ente da federação que, sozinho, continuará a não dar conta de atender a demanda.

Afinal, diante das incontestáveis limitações orçamentárias e da falta de eficiência da Federação em distribuir tarefas e recursos, o melhor caminho a ser seguido para otimizar as políticas públicas é ajudar na promoção do diálogo entre os responsáveis por cada área do SUS, com o fim de criar um sistema coerente, transparente, com qualidade crescente e, assim, estimular a construção de políticas públicas planejadas, local e regionalmente, legítimas e duradouras.

\section{Referências}

ALMEIDA, Fernanda Dias Menezes de. Competências na Constituição de 1988. São Paulo: Atlas, 2013.

BUCCI, Maria Paula Dallari. Fundamentos para uma teoria jurídica das políticas públicas. São Paulo: Saraiva, 2013.

HOWLETT, Michael; RAMESH, M.; PERL, Anthony. Política pública: seus ciclos e subsistemas: uma abordagem geral. Rio de Janeiro: Elsevier, 2013.

PELOTAS. Conselho Municipal de Saúde. Relatório sobre o Pronto Socorro de Pelotas, elaborado pelo Conselho Municipal de Saúde em atendimento à deliberação de plenária realizada em 21 de dezembro de 2006 (Ata 27/2006). Disponível em: <http://www.pelotas. rs.gov.br/cmspel/relatorio_psp.pdf >. Acesso em: 22 set. 2015.

${ }^{27}$ HOWLETT, Michael; RAMESH, M.; PERL, Anthony. op. cit., p. 216. 
A construção das políticas públicas de saúde

RAIS, Diogo. A sociedade e o Supremo Tribunal Federal: o caso das audiências públicas. São Paulo: Fórum, 2012.

RAMOS, Dircêo Torreccillas. Federação: tarefas, recursos, prazos, controle para combater a corrupção. In: RAMOS, Dircêo Torreccillas (Org.). O federalista atual: teoria do federalismo. Belo Horizonte: Arraes Editores, 2013.

SOUZA, Luciane Moessa de. Meios consensuais de solução de conflitos envolvendo entes públicos: negociação, mediação e conciliação. Belo Horizonte: Ed. Fórum, 2012.

Patricia Ulson Pizarro Werner - Doutora, mestre e graduada em em Direito pela Pontifícia Universidade Católica de São Paulo. Membro de corpo editorial da Revista da Procuradoria Geral do Estado de São Paulo. Procuradora do Estado.São Paulo/SP, Brasil. E-mail: pwerner@sp.gov.br. 